\title{
Denture Stomatitis : A Comprehensive Diagnostic Approach
}

\author{
Aniruddh Menon ${ }^{1}$ and Dhanraj Ganapathy ${ }^{2}$ \\ ${ }^{1}$ Department of Prosthodontics, Saveetha Dental College and Hospitals Saveetha Institute \\ of Medical and Technical Sciences Saveetha University, Chennai-77, India \\ ${ }^{2}$ Professor and Head of Department, Department of Prosthodontics, Saveetha Dental College and Hospitals \\ Saveetha Institute of Medical and Technical Sciences Saveetha University, Chennai-77, India
}

\begin{abstract}
Denture stomatitis is one of the most commonly recurring problems of the denture wearers. Denture stomatitis is a term used to describe an array of pathological changes in the oral mucosa in relation to the denture bearing tissues. The aetiology of the disease includes infection, trauma and probably a defect in the host defence mechanism as well. Current school of thought suggests an interplay of most of these factors in the pathogenesis and development of the disease. The extent of interplay of these factors is still a controversy. Candida albicans has been implicated as the causative organism. However, in the light of recent research it is debatable if it is the only causative organism for denture stomatitis. Recently, cases resistant to antifungal therapy have been reported. In such cases other microorganisms have been isolated. At the moment, comprehensive management includes good denture hygiene together with antifungal or antibacterial therapy and correction of denture faults.
\end{abstract}

KEY WORDS: DENTURE,FUNGAL,STOMATITIS,TISSUES.

\section{INTRODUCTION}

Previously our department has published extensive research on various aspects of prosthetic dentistry ('Evaluation of Corrosive Behavior of Four Nickel-chromium Alloys in Artificial Saliva by Cyclic Polarization Test:An in vitro Study', 2017; Ganapathy, Kannan and Venugopalan, 2017; Jain, 2017a, 2017b; Ranganathan, Ganapathy and Jain, 2017; Ariga et al., 2018; Gupta, Ariga and Deogade, 2018; Anbu et al., 2019; Ashok and Ganapathy, 2019;

\section{ARTICLE INFORMATION}

*Corresponding Author: prasadjoness.ece@krct.ac.in Received 25th June 2020 Accepted after revision 9th August 2020 Print ISSN: 0974-6455 Online ISSN: 2321-4007 CODEN: BBRCBA

Thomson Reuters ISI Web of Science Clarivate Analytics USA and Crossref Indexed Journal

\section{Clarivate}

NAAS Journal Score 2020 (4.31) SJIF: 2020 (7.728)

A Society of Science and Nature Publication,

Bhopal India 2020. All rights reserved.

Online Contents Available at: http//www.bbrc.in/

Doi: http://dx.doi.org/10.21786/bbrc/13.7/5
Duraisamy et al., 2019; Varghese, Ramesh and Veeraiyan, 2019), this vast research experience has inspired us to research about Denture Stomatitis. Denture stomatitis is a frequent aftermath that is noted in denturewearing patients.(BUDTZ-JöRGENSEN, 1974) Microbial studies indicate that the condition is associated with a quantitative as well as qualitative increase of yeasts on the mucosal surface of the denture.

Denture stomatitis is a term used to describe an array of pathological changes in the oral mucosa in relation to the denture bearing tissues(NEWTON and V, 1962).These changes are characterized by an area of erythema and are found under complete or partial dentures in both dental arches, but more infrequently in the maxilla. The occlusion of the denture bearing mucosa by the denture prevents the normal cleansing action provided by the

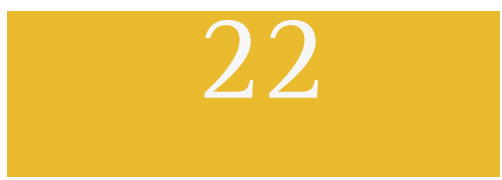


movement of the tongue and the flow of saliva. This may explain the higher incidence of denture stomatitis in the maxilla. Although the tissues appear raw and inflamed, the patient is rarely aware of the condition and seldom complains of pain.

Prevalence: The exact point prevalence of denture stomatitis is not known. Various authors have quoted figures ranging from 11 per cent to 67 per cent. Nyquist(Nyquist, 1953)found that 27 per cent of 601 cases that were included in the study were affected. Chrigstrom, Hedegard and Markens (Chrigström, Hedegård and Marken, 1970) found that the prevalence of denture stomatitis was only 11 per cent among 160 Swedish pensioners. Love, Gusta and Nixon(Love, Goska and Mixson, 1967) found that 43 per cent of 522 denture wearers that were affected. BudtzJorgensen (Budtz-jørgensen, 1972) found the prevalence of denture stomatitis to be 67 per cent of 303 patients. The lesions were more prevalent in women than in men through different studies and the relative frequency declined with age.(Nyquist, 1953)

Aetiology: There are three main features which may be implicated in the initiation and progression of denture stomatitis. They are:

1. Trauma.

2. Infection.

3. Allergy.

Nyquist (Nyquist, 1953) considered trauma to be the most common and dominant aetiological factor, as denture stomatitis was seen frequently under ill-fitting dentures with a traumatic occlusion. Investigators that believe trauma to be a significant aetiological factor for denture stomatitis have advocated the use of tissue conditioners and the construction of new, properly fitting dentures replacing the ill fitting ones (CAHN and LR, 1936; Nyquist, 1953). It was shown that by removing trauma, lesions of the localized simple type (Type I) were completely or partly healed. On the other hand, candidainduced lesions were almost unaffected by prosthetic treatment.(CAWSON and A, 1963)

The first author to relate the presence of Candida species with denture stomatitis was Cahn.(CAHN and LR, 1936) There is conflicting evidence as to whether wearing of dentures at night influences the occurence of denture stomatitis. Nyquist (Nyquist, 1953) found complications to be more common and Love, Gusta and Nixon(Love, Goska and Mixson, 1967) found it more severe in subjects who did not remove their dentures at night. On the other hand, Budtz-Jorgensen and Bertram (Budtz-Jørgensen and Bertram, 1970) found no difference in the denture wearing frequency of a group with denture stomatitis as compared with a control group. However, Williamson (Williamson, 1972) showed that patients who wore their dentures at night had a tenfold increase in the number of candida colonies as compared with patients who wore their dentures in the daytime only. All of these studies suggest that Candida albicans is the main causative organism in denture stomatitis. Candida albicans is the most common and most invasive fungal organism in the oral cavity. It is more adherent to human buccal epithelial cells than any other Candida species.(King, Lee and Morris, 1980).

The yeast form of most dimorphic hngi is considered to be the pathogenic form but an association between the presence of filamentous forms of Candida and candidiasis has been noted.(Kimura and Pearsall, 1980)The yeast form of Candida albicans may be pathogenic and with clinical infection, the altered micro-environment favours change to the filamentous form. The pathogenic effects of Candida albicans in candidiasis are uncertain. Hasenclever and Mitchell (Hasenclever and Mitchell, 1962) suggested that Candida albicans produces endotoxin, and immunity to endotoxin may confer immunity to the disease.

However, Chattaway, Odds and Barlow(Chattaway, Odds and Barlow, 1971)found that the levels of endotoxin found in vivo may not be sufficient to produce toxic effects. Pugh and Cawson(Pugh, Ra and Others, 1977) stated that invasion of epithelial cells by Candida albicans depended on hydrolytic enzyme activity and mechanical forces. Some evidence suggested that toxic products of the organism do not initiate candidiasis but act as irritants, aggravating tissue lesions. Cell-mediated immunity plays a role in the protection against Candida, as up to 80 per cent of the population without evidence of infection have cellular immunity to Candida antigen. (Taschdjian, Seelig and Kozinn, 1973).

Several reports indicate that specific immune imbalance in response to Candida albicans may play a role in the pathogenesis of oral candidiasis. Indeed, humoral antibodies in excess may suppress the cell mediated response.(Mackie, Parratt and Jenkins, 1978) There are studies in which other microbes such as D. pneumoniae, Streptococcus mitis, Streptococcus salivarius, Streptococcus faecalis, haemolytic Streptococcus and Klebsiella have been isolated.(Reenen and JF, 1973; Holbrook, Russell and Others, 1979) MacFarlane and Helenerake (MacFarlane, Tw and Sj, 1976)isolated Staphylococcus aureus in 79 per cent and Candida albicans in 44 per cent of angular cheilitis lesions. Helstrom and Balish (Helstrom and Balish, 1979) suggested that Candida extract may have contained materials which simply improved the nutritional environment for the infecting micro-organism rather than resulting in suppression of host immune responses. All these later studies may implicate other microbes in the aetiology of denture stomatitis. 
Therefore, there remain questions that are unanswered

1. If, in fact, Candida infection causes suppression of cell-mediated immunity, then an obvious question about the cause and effect relationship will be raised. That is, which arises first, the immune defect or the Candidal infection?

2. Is Candida albicans the primary invading microorganism or does Candida make the environment suitable for other microorganisms to flourish and exert a pathogenic effect in the chronic inflammatory process?

3. Are Candida albicans and other microorganisms secondary invaders of traumatized tissues?

Allergy to denture base material was thought to be a possible cause of denture stomatitis (Smith and Bains, 1956) However, any inflammatory response, due to the leaching out of monomer, was transient and occurred immediately. Therefore it would be expected that any allergic response would be immediate, whereas in denture stomatitis the inflammation occurs under old and unkempt dentures.

The alteration from commensalism to parasitism of Candida albicans may be due to changes in the host rather than in the parasites. Candida infection can arise either because conditions are favourable for growth of the hngus or because of a depressed defence mechanism. (Austin and Rm, 1980)

1. Malnutrition: The importance of iron in maintaining the health and capability for repair of oral tissues is well known. Iron deficiency causes an impairment of the irondependent enzyme system, thereby upsetting metabolism and reproduction of epithelial cells and is thus favourable to the growth of Candida albicans. Joynson and coworkers (Joynson et al., 1972)demonstrated an impaired cell mediated immune response to Candida albicans in iron-deficient patients. The immune response was restored once the iron level was normal. Other systemic disorders like diabetes mellitus and leukaemia may contribute to the incidence of denture stomatitis. A high intake of carbohydrate was presumed to be a direct cause of oral candidiasis in denture wearers. That a high carbohydrate intake might predispose to a candida-induced stomatitis was suggested in an in vitro study showing that the addition of glucose to nutrient-depleted saliva produced an exceptional growth of Candida albicans, despite the presence of a nutrient competing bacterial (Knight and Fletcher, 1971)

2. Oral antibiotics: Antibiotics increase the susceptibility to infections with Candida albicans. Systemic antibiotics do not affect Candida in the healthy edentulous mouth as the concentration of antibiotics in the oral cavity must be above a certain level to alter the balance of the mixed oral flora. However, if the barrier action of the epithelium breaks down because of inflammation, antibiotics will gain access to the oral microflora, hence encouraging Candida infection. Increasing use of antibiotics, corticosteroids and immunosuppressive drugs may result in an increase in oral candidiasis.

3. Hormonal imbalance: Neil stated that there might be an endocrine influence in denture stomatitis. He based it on the findings that this condition was more commonly found in women than in men.During a month period he saw nine cases, all of whom were women who had passed menopause. He also noted that there was a traumatic factor. He found that in all these patients there was an altered activity of the adrenal cortex. The neutral ketosteroid excretion of the urine and blood ascorbic acid levels were abnormal in affected patients. This supported the view that the tolerance of oral tissues to trauma was altered when there was a hormonal imbalance.

Diagnostic considerations: Diagnosis of denture stomatitis depends upon the clinical signs, the presence of the organism in a direct smear, the salivary culture of a significant number of micro-organisms and the presence of specific antibodies to Candida antigen.

Clinical features: Denture stomatitis may be graded clinically into three types.(Stickle, Kaufman and Blumer, 1972)

Type I: Pinpoint hyperaemia and diffUse inflammation of a limited area of the mucosa in an otherwise normal tissue.

Type II:Diffuse erythema of most of the denture bearing area.

Type III: Granular inflammation or inflammatory papillary hyperplasia. The mucosa has a nodular appearance with a hyperaemic surface normally present over the entire denture-bearing area but is more commonly restricted to the central areas and, in particular, under relief areas.

If untreated, it is felt that the disease will progress from Type I through Type II to Type III. There is, however, some doubt concerning this progression. Type I has been related to denture trauma only, as compared with Type II and III which have a multi-factorial aetiology. Denture stomatitis is associated frequently with angular cheilitis and glossitis and the patient may complain of a burning sensation in the palate However, many patients may not be aware of the condition.

Laboratory diagnosis of denture stomatitis: Clinical diagnosis of denture stomatitis can be confirmed by mycological and immunological examinations. Several methods have been used in identification. 
1. Mycological examination: (a) Microscopic examination of smear Direct smears are prepared from scrapings taken with a sterile wooden spatula from the palatal mucosa and the fitting surface of the denture. The fured smears are stained with Periodic acid-Schiff (PAS), which demonstrates the presence or otherwise of the yeast cells. Another method is to obtain scrapings of the oral mucosa with a wooden spatula, smear the material obtained on a glass slide and place immediately in 95 per cent ethanol and stain with Papanicolaou stain. A differential count is made of 200 randomly selected cells on each slide. In denture stomatitis the differential count consists entirely of nucleated cells.

(b) Isolation and identification by culture could be employed. There are two types of culture technique that

1. Imprint cultures: Sterile square pieces of plastic foam are dipped in Sabouraud's broth and placed on various oral mucosal and denture surfaces. The pieces of plastic foam are then pressed firmly onto a Sabouraud's agar plate. They are then incubated for 48 hours at 37 "C. After incubation, the Candida colonies are counted.

2. Replica cultures: Two layers of plastic foam are sandwiched between the upper denture and palatal mucosa. The two layers of foam are pressed into separate Sabouraud's agar plates and incubated at 37 "C for 48 hours and then examined for the presence of Candida albicans." An alternative method of making replica cultures is by making a Sabouraud's cast from an alginate impression of the materials

Salivary counts: Both stimulated and unstimulated saliva with the dentures in the mouth and out of the mouth can be used. Dilutions of the saliva are prepared in saline and samples placed on a Sabouraud's dextrose agar plate and spread with a Pasteur spreader. The plates are incubated aerobically at $37^{\circ} \mathrm{C}$ for 48 hours. The Candida colonies are then counted to obtain the number of colonies per $\mathrm{mL}$ of saliva.

\section{CONCLUSION}

Review of the literature has unravelled the possible role of a mixed microflora in the pathogenesis of denture stomatitis. Extensive work in the field of immunology revealed that cell-mediated immunity is probably the important defence mechanism. Humoral antibodies have been detected in the diseased state which may indicate a response to antigenic loading. However, such antibody levels decreased following antifungal therapy. This may confirm the non-protective role of humoral antibodies and the possible aetiological role of Candida albicans. Management involves denture hygiene in conjunction with anti-fungal therapy and correction of denture faults.
Presently, denture hygiene has not been well publicized to individuals. This is unfortunate as the effects of denture cleanliness on oral health have been explored for more than 30 years. Therefore, dentists should accept responsibility for providing adequate instruction in denture home care as an essential part of patient preparation to receive dentures. Recall appointments to assess and reinforce denture hygiene are a requirement. Such a programme will be beneficial to both the patient and the dentist in preserving the health of the denturebearing tissue.

\section{ACKNOWLEDGEMENTS}

No Acknowledgements

\section{Conflict of Interest: No Conflict of Interest}

\section{REFERENCES}

Anbu, R. T. et al. (2019) 'Comparison of the Efficacy of Three Different Bone Regeneration Materials: An Animal Study', European journal of dentistry, 13(1), pp. 22-28.

Ariga, P. et al. (2018) 'Determination of Correlation of Width of Maxillary Anterior Teeth using Extraoral and Intraoral Factors in Indian Population: A Systematic Review', World Journal of Dentistry, 9(1), pp. 68-75.

Ashok, V. and Ganapathy, D. (2019) 'A geometrical method to classify face forms', Journal of oral biology and craniofacial research, 9(3), pp. 232-235.

Austin, A. T. and Rm, B. (1980) 'The level of residual monomer in acrylic denture base materials'. pascalfrancis.inist.fr. Available at: https://pascal-francis.inist. fr/vibad/index.php?action=getRecordDetailctidt=PASC AL8110156890.

Budtz-jørgensen, E. (1972) 'Denture Stomatitis V Candida Agglutinins in Human Sera', Acta odontologica Scandinavica. Taylor \&t Francis, 30(3), pp. 313-325. BUDTZ-JöRGENSEN, E. (1974) 'The significance of Candida albicans in denture stomatitis', European journal of oral sciences. Wiley Online Library, 82(2), pp. 151-190.

Budtz-Jørgensen, E. and Bertram, U. (1970) 'Denture Stomatitis I. The Etiology in Relation to Trauma and Infection', Acta odontologica Scandinavica. Taylor \& Francis, 28(1), pp. 71-92.

CAHN and LR (1936) 'The denture sore mouth', Annals of dentistry. ci.nii.ac.jp, 3, pp. 33-36.

CAWSON and A, R. (1963) 'Denture sore mouth and angular cheilitis. Oral candidiasis in adults', British dental journal. ci.nii.ac.jp, 115, pp. 441-449.

Chattaway, F. W., Odds, F. C. and Barlow, A. J. E. (1971) 'An examination of the production of hydrolytic enzymes and toxins by pathogenic strains of Candida albicans', Microbiology. Microbiology Society, 67(3), pp. 255-263.

Chrigström, K., Hedegård, B. and Marken, K. E. (1970) 'Gerodontologiska studier. IV. Oralstatus och vårdbehov vid en vårdhems-och pensionärsinstitution i Stockholm', 
Sven. Tandlaek. Tidskr, 63, pp. 981-995.

Duraisamy, R. et al. (2019) 'Compatibility of Nonoriginal Abutments With Implants: Evaluation of Microgap at the Implant-Abutment Interface, With Original and Nonoriginal Abutments', Implant dentistry, 28(3), pp. 289-295.

Evaluation of Corrosive Behavior of Four Nickelchromium Alloys in Artificial Saliva by Cyclic Polarization Test:An in vitro Study' (2017) World Journal of Dentistry, 8(6), pp. 477-482.

Ganapathy, D. M., Kannan, A. and Venugopalan, S. (2017) 'Effect of Coated Surfaces influencing Screw Loosening in Implants: A Systematic Review and Meta-analysis', World Journal of Dentistry, 8(6), pp. 496-502.

Gupta, P., Ariga, P. and Deogade, S. C. (2018) 'Effect of Monopoly-coating Agent on the Surface Roughness of a Tissue Conditioner Subjected to Cleansing and Disinfection: A Contact Profilometric Study', Contemporary clinical dentistry, 9(Suppl 1), pp. S122S126.

Hasenclever, H. F. and Mitchell, W. O. (1962) 'Production in mice of tolerance to the toxic manifestations of Candida albicans', Journal of bacteriology. Am Soc Microbiol. Available at: https://jb.asm.org/ content/84/3/402.short.

Helstrom, P. B. and Balish, E. (1979) 'Effect of oral tetracycline, the microbial flora, and the athymic state on gastrointestinal colonization and infection of BALB/c mice with Candida albicans', Infection and immunity. Am Soc Microbiol. Available at: https://iai.asm.org/ content/23/3/764.short.

Holbrook, W. P., Russell, C. and Others (1979) 'Klebsiella in patients with denture stomatitis', British dental journal. cabdirect.org, 146(1), pp. 3-4.

Jain, A. R. (2017a) 'Clinical and Functional Outcomes of Implant Prostheses in Fibula Free Flaps', World Journal of Dentistry, 8(3), pp. 171-176.

Jain, A. R. (2017b) 'Prevalence of Partial Edentulousness and Treatment needs in Rural Population of South India', World Journal of Dentistry, 8(3), pp. 213-217. Joynson, D. H. M. et al. (1972) 'Defect of cell-mediated immunity in patients with iron-deficiency anaemia', The Lancet. Elsevier, 300(7786), pp. 1058-1059.

Kimura, L. H. and Pearsall, N. N. (1980) 'Relationship between germination of Candida albicans and increased adherence to human buccal epithelial cells', Infection and immunity. Am Soc Microbiol. Available at: https:// iai.asm.org/content/28/2/464.short.

King, R. D., Lee, J. C. and Morris, A. L. (1980) 'Adherence of Candida albicans and other Candida species to mucosal epithelial cells', Infection and immunity. Am Soc Microbiol. Available at: https://iai.asm.org/ content/27/2/667.short.

Knight, L. and Fletcher, J. (1971) 'Growth of Candida albicans in Saliva: Stimulation by Glucose Associated with Antibiotics, Corticosteroids, and Diabetes Mellitus',
The Journal of infectious diseases. Oxford University Press, 123(4), pp. 371-377.

Love, W. D., Goska, F. A. and Mixson, R. J. (1967) 'The etiology of mucosal inflammation associated with dentures', The Journal of prosthetic dentistry. Elsevier, 18(6), pp. 515-527.

MacFarlane, T. W., Tw, M. and Sj, H. (1976) 'The microbiology of angular cheilitis'. pascal-francis.inist. fr. Available at: https://pascal-francis.inist.fr/vibad/ index.php?action=getRecordDetailetidt=PASCAL7650 270614.

Mackie, R. M., Parratt, D. and Jenkins, W. M. M. (1978) 'The relationship between immunological parameters and response to therapy in resistant oral candidosis', The British journal of dermatology. Wiley Online Library, 98(3), pp. 343-348.

NEWTON and V, A. (1962) 'Denture sore mouth', British dental journal. ci.nii.ac.jp, 112, pp. 357-360.

Nyquist, G. (1953) 'The influence of denture hygiene and the bacterial flora on the condition of the oral mucosa in full denture cases', Acta odontologica Scandinavica. Taylor \&t Francis, 11(1), pp. 24-60.

Pugh, D., Ra, C. and Others (1977) 'The cytochemical localization of acid hydrolases in four common fungi'. pascal-francis.inist.fr. Available at: https://pascalfrancis.inist.fr/vibad/index.php?action=getRecordDeta ilctidt=PASCAL7810412934.

Ranganathan, H., Ganapathy, D. M. and Jain, A. R. (2017) 'Cervical and Incisal Marginal Discrepancy in Ceramic Laminate Veneering Materials: A SEM Analysis', Contemporary clinical dentistry, 8(2), pp. 272-278.

Reenen, V. A. N. and JF (1973) 'Microbiologic studies on denture stomatitis', The Journal of prosthetic dentistry. ci.nii.ac.jp, 30, pp. 493-505.

Smith, D. C. and Bains, M. E. D. (1956) 'The Detection and Estimation of Residual Monomer in Polymethyl Methacrylate', Journal of dental research. SAGE Publications Inc, 35(1), pp. 16-24.

Stickle, D., Kaufman, L. and Blumer, S. O. (1972) 'Comparison of a newly developed latex agglutination test and an immunodiffusion test in the diagnosis of systemic candidiasis', Applied. Am Soc Microbiol. Available at: https://aem.asm.org/content/23/3/490. short.

Taschdjian, C. L., Seelig, M. S. and Kozinn, P. J. (1973) 'Serological Diagnosis of Candidal Infections', CRC critical reviews in clinical laboratory sciences. Taylor Ct Francis, 4(1), pp. 19-59.

Varghese, S. S., Ramesh, A. and Veeraiyan, D. N. (2019) 'Blended Module-Based Teaching in Biostatistics and Research Methodology: A Retrospective Study with Postgraduate Dental Students', Journal of dental education, 83(4), pp. 445-450.

Williamson, J. J. (1972) 'Diurnal variation of Candida albicans counts in saliva', Australian dental journal. Wiley Online Library, 17(1), pp. 54-60. 